\title{
Physical and Psychological Changes Experienced by Women after Menopause
}

\author{
Meenu Sirohi* and Veenu Sangwan \\ Department of Foods \& Nutrition, CCS Haryana Agricultural University, \\ Hisar-125004, India \\ *Corresponding author
}

\section{A B S T R A C T}

\section{Keywords}

Health, Menopause, Physical, Weight, Women

Article Info

Accepted:

17 September 2019

Available Online:

10 October 2019
Menopause is one of the stages of life for women that cause extensive variety of symptoms, effects, and sometimes restraints on the quality of life of post menopausal women. The present study was designed to assess the physical and psychological changes experienced by Postmenopausal women of urban and rural area of Hisar district Haryana instantly after menopause. The study included 200 women (100 urban and 100 rural) in the age group of 45 to 60 years having natural menopause more than one year. All the subjects were permanent residents of the Haryana. During study various physical and psychological changes felt by women were observed which affects the health status of post menopausal women. All such type of changes perceived by women was asked from each subject by paying repeated visits to the study subjects. The results showed that majority of the subjects $(50 \%)$ gained weight more than five $\mathrm{kg}$ after menopause, forty nine percent had reduced height about half an inch, most of the subjects $(79 \%)$ had poor physical performance, 58 percent had experienced low immunity, 78 percent had experienced high appetite and majority (49\%) of the subjects were feeling happy after menopause while thirty nine percent did not feel happy.

\section{Introduction}

Women after menopause often experience one or more physical and psychological alterations in their body (Hagi et al., 2017). Menopausal transition causes menopausal symptoms like hot flushes, night sweats, anxiety etc, changes in body composition such as overweight or obesity, musculoskeletal complaints,
(Heinemann et al., 2004) other changes like increase in appetite, etc. These symptoms can be severe enough to negatively impact quality and quantity of life by affecting their food consumption pattern, their work performance, socio economic status during and after menopause (Leblanc et al., 2014). It has been observed that reduction in the secretion of estrogen hormone along with other factors like 
diet, lack of physical activity, etc causes menopause related changes among post menopausal women. Menopause has been considered as an emerging issue which is known to affect the body fat composition and health of women. Khokhar et al., (2010) and Schoppen et al., (2005) have showed a link between menopause and body mass index and found out that, during this phase, the prevalence of obesity was high as a result of changes in body fat composition and a decrease in oestrogen levels. Wing et al., (1991) has also reported gain in weight among women after their menopause. Kapoor et al., (2017) reported alterations in fat distribution among postmenopausal women from gynoid to android which make them more prone to the risk of various metabolic syndromes and noncommunicable diseases. It has been observed that women after menopause showed more rapid decline in their physical performance in comparison to men of same age. Such type of difference occurs may be due to the hormonal changes that occur during the menopausal years (Bondarev et al., 2018). Hardy et al., (2018) demonstrated that various menopausal symptoms like vasomotor symptoms affect the work efficiency of post menopausal women. Camara et al., (2015) revealed that perimenopausal and postmenopausal women have worse physical function than premenopausal women. It has been found that reduction in the secretion of female hormone estrogen affects appetite and causes high food intake after menopause and in this way increases high energy intake Karine et al., (2016). High energy intake and low physical exercise for longer time increase the risk of overweight among post menopausal women.

\section{Materials and Methods}

Total 200 post menopausal women (100 from urban and 100 from rural) between the age group of 45-60 years were selected randomly. The inclusion criteria consisted of a cessation of menopause naturally for at least more than one year. The limitation of the study was the exclusion of women having surgical menopause. For obtaining data from urban area Hisar city and for rural area three villages namely Dabra (Hisar 1 block), Dhana Kalan and Mehanda (Hansi 1 block) were selected purposively for the collection of data. Data related to various physical and psychological changes like gain in weight, reduction in height, impact on appetite, reduction in work performance and immunity etc felt by urban and rural women after menopause was obtained with the help of structured questionnaire-cum-interview schedule by paying repeated visits to the study area. Data collected was organized, compiled, tabulated, analyzed and interpreted by taken in consideration the objectives of study. SPSS statistical analysis software was used.

\section{Results and Discussion}

The findings related to physical and psychological changes experienced by postmenopausal women immediately after menopause depicted in Table 1 indicated that majority of the urban $(54 \%)$ and rural $(45 \%)$ post menopausal women gained more than 5 $\mathrm{kg}$ weight after menopause followed by 24 and 9 percent of urban and 23 and 11 percent of rural subjects who gained $4-5$ and $2-3 \mathrm{~kg}$ after menopause, respectively. Thirteen percent of urban and 21 percent of rural subjects did not gain weight after menopause. The results of the present study are in support of the other scientists (Deotale et al., (2015) and Panotopoulos et al., (1997) who also reported weight gain after menopause. As many as 79 percent of urban and 57 percent of rural post menopausal women gained weight in more than one year while 8 and 22 percent of urban and rural subjects gained weight within one year of age, respectively. It was also found that height of majority of the urban $(51 \%)$ and rural (47\%) subjects reduced by 
about half an inch with passage of time. Height of 8 to 10 percent of post menopausal women reduced by about one inch with time while the height of 41 to 43 percent of subjects was not affected. Kaur et al., (2014) accounted that height was reduced among post-menopausal women of Punjab from 154.4 $\mathrm{cm}$ to $152.25 \mathrm{~cm}$ and also reported that it continuously decreased from 60 year onwards among all post menopausal women.

Table.1 Physical and psychological changes felt by urban and rural postmenopausal women after menopause

\begin{tabular}{|c|c|c|c|}
\hline Changes (\%) & $\operatorname{Urban}(n=100)$ & Rural (n=100) & Total $(n=200)$ \\
\hline \multicolumn{4}{|c|}{ Gain in Weight after menopause } \\
\hline $2-3$ & 9 & 11 & $20(10)$ \\
\hline 4-5 & 24 & 23 & $47(23.5)$ \\
\hline$>5$ & 54 & 45 & 99 (49.5) \\
\hline No change & 13 & 21 & $34(17)$ \\
\hline \multicolumn{4}{|c|}{ Duration in gaining weight $(\mathbf{k g})$} \\
\hline Up to 1 year & 8 & 22 & $30(15)$ \\
\hline >1year & 79 & 57 & $136(68)$ \\
\hline No weight gain & 13 & 21 & $34(17)$ \\
\hline \multicolumn{4}{|c|}{ Reduction in height } \\
\hline $1 / 2$ inch & 51 & 47 & $98(49)$ \\
\hline 1 inch & 8 & 10 & $18(9)$ \\
\hline$>1$ & - & - & - \\
\hline No change & 41 & 43 & $84(42)$ \\
\hline \multicolumn{4}{|c|}{ Time duration in reduction of height } \\
\hline Up to1 year & - & - & - \\
\hline >1year & 59 & 57 & $116(58)$ \\
\hline No change & 41 & 43 & $84(42)$ \\
\hline \multicolumn{4}{|c|}{ Reduction in physical performance } \\
\hline Yes & 77 & 81 & $158(79)$ \\
\hline No & 23 & 19 & $42(21)$ \\
\hline \multicolumn{4}{|c|}{ Reduction in immunity } \\
\hline Yes & 39 & 76 & $115(57.5)$ \\
\hline No & 61 & 24 & $85(42.5)$ \\
\hline \multicolumn{4}{|c|}{ Impact on appetite } \\
\hline Increased & 79 & 72 & $151(75.5)$ \\
\hline Decreased & 8 & 19 & $27(13.5)$ \\
\hline Normal & 13 & 9 & $22(11)$ \\
\hline \multicolumn{4}{|c|}{ Feeling after menopause } \\
\hline Happy & 63 & 35 & $98(49)$ \\
\hline Sad & 16 & 62 & $78(39)$ \\
\hline Normal & 21 & 3 & $24(12)$ \\
\hline
\end{tabular}

Values in parenthesis indicate percentage 
The loss of height among women after menopause occurs due to osteoporosis in which vertebrae collapse. After menopause the occurrence of osteoporosis occurs due to deficiency of calcium and vitamin $\mathrm{D}$ rich foods in diet or poor absorption in the small intestine, high sodium to potassium ratio and low calcium to phosphorus ratio in diet, high intake of caffeinated and phosphoric acid rich beverages, no sun exposure, low secretion of estrogen hormone etc.

It was also found that the physical performance of majority of the urban $(77 \%)$ and rural $(81 \%)$ postmenopausal women reduced. Only 39 percent of urban and rural (76\%) subjects reported reduction in their immunity. The findings of the study also showed that appetite of most of the urban (79\%) and rural (72\%) subjects increased after menopause, while 8 and 19 percent of urban and rural subjects reported reduction in their appetite. The present findings are in close proximity of Karine et al., (2016) who reported that the desire to eat, appetite and prospective food consumption increased during the menopausal transition and remained higher in the postmenopausal years. After menopause majority of the urban (63\%) subjects reported feeling of happiness after menopause due to freedom from menstruation hassle. As many as 62 percent of the rural subjects did not feel happy and this may be due to their reduction in physical performance, gain in weight, reduction in height and various health complications associated with menopause which inversely affect their socio economic status.

The values related to various physical and psychological alterations experienced by post menopausal women were high among both the urban and rural subjects. Menopausal women gained weight due to hormonal changes that occur during menopause or during mid-life transition. Various factors like modification in life style, reduced physical activity, dietary factors like high energy intake due to increased appetite and alteration in body fat composition of the individual could also be responsible for weight gain. Faulty dietary habits along with poor absorption of calcium and vitamin $\mathrm{D}$ causes collapse in vertebrae due to which the height of post menopausal women begins to decrease and their work efficiency also begins to low due to such metabolic disturbances.

\section{References}

Bondarev, D., Laakkonen, E.K., Finni, T., Kokko, K., Kujala, U.M., Aukee, P., Vuokko Kovanen, and Sipila, S. (2018). Physical performance in relation to menopause status and physical activity. Menopause: The Journal of The North American Menopause Society, 25(12): 1432-1441.

Camara., S.M.A., Maria Zunzunegui M.A., Pirkle, C., Moreira, M.A. and Álvaro C. C. Maciel, A.C.C. (2015). Menopausal Status and Physical Performance in Middle Aged Women: A Cross-Sectional Community-Based Study in Northeast Brazil. PLoS ONE, 10(3):1-12.

Deotale, M., Ranganathan, U., Mankeshwar, R., and Akarte, S. (2015). Study of epidemiological features of health problems in perimenopausal and postmenopausal women in an urban community. International Journal of Medicine and Public Health, 5(2): $147 \mathrm{p}$.

Haghi, H. B., Hakimi, S., Mirghafourvand, M., Charandabi, S. M. A., and Farahbakhsh, M. (2017). Comparison of quality of life between urban and rural menopause women and its predictors: A population base study. International Journal of Women's Health and Reproduction Sciences, 
5(2): 137-142.

Hardy,C., Thorne, E., Griffiths, A. and Hunter, M.S. (2018). Work outcomes in midlife women: the impact of menopause, work stress and working environment. Women's Midlife Health, 4(3): 2-8.

Heinemann, K., Ruebig, A., Potthoff, P., Schneider, H.P. and Strelow, F. (2004). The Menopause Rating Scale (MRS) scale: a methodological review. Health and Quality of Life Outcomes, 2(45):1-8.

Kapoor, E., Collazo-Clavell, M. L. and Faubion, S.S. (2017). Weight Gain in Women at Midlife: A Concise Review of the Pathophysiology and Strategies for Management. Mayo Clinic Proceedings, 92(10):1552-1558.

Karine, D., Denis, P., Rémi, R., Irene, S., Martin, B., Marc, L.J. and Éric, D. (2016). Effects of the Menopausal Transition on Dietary Intake and Appetite. A MONET Group Study. European Journal of Clinical Nutrition, 68(2): 271-276.

Kaur, S., Mehta, P., and Kaur, G. (2014). Anthropometric Profile and Menopausal Age of 40 to 80 Year Old Women of Punjab: A Study. Journal of Life Sciences, 6(1-2): 1-5.

Khokhar, K.K., Kaur, G. and Sidhu, S. (2010)
Prevalence of obesity in working premenopausal and postmenopausal women of Jalandhar district Punjab. Journal of Human Ecology, 29: 57-62.

LeBlanc, E. S., Desai, M., Perrin, N., Wactawski-Wende, J., Manson, J. E., Cauley, J.A., Michael, Y.L., Tang, J., Womack, C., Song, Y., Johnson, K. C., Sullivan, M. J. O. Woods, N. and Stefanick, M. L. (2014). Vitamin D levels and menopause-related symptoms. Menopause, 21 (11): 11971203.

Panotopoulos, G., Raison, J., Ruiz, J.C., GuyGrandB. and Basdevant A. (1997). Weight gain at the time of menopause. European Society for Human Reproduction \& Embryology, 12 (1):126-133.

Schoppen, S., Carbajal, Á., Pérez-Granados, A. M., Vivas, F., and Vaquero, M. P. (2005). Food, energy and macronutrient intake of postmenopausal women from a menopause program. Nutricion Hospitalaria, 20(2): 101-109.

Wing, R.R., Matthews, K.A., Kuller, L.H., Meilahn, E.N. and Plantinga, P.L. (1991) Weight gain at the time of menopause. Archives of International Medicine, 151(1):97-102.

\section{How to cite this article:}

Meenu Sirohi and Veenu Sangwan. 2019. Physical and Psychological Changes Experienced by Women After Menopause. Int.J.Curr.Microbiol.App.Sci. 8(10): 2437-2441. doi: https://doi.org/10.20546/ijcmas.2019.810.283 